Oral presentation

\title{
Reducing rigid-body error in a functional technique to determine ankle joint axes J Leitch $^{1}$, J Stebbins ${ }^{2}$ and AB Zavatsky*1
}

\author{
Address: ${ }^{1}$ Department of Engineering Science, University of Oxford, Oxford, UK and ${ }^{2}$ Oxford Gait Laboratory, Nuffield Orthopaedic Centre NHS \\ Trust, Oxford, UK \\ Email: AB Zavatsky* - amy.zavatsky@eng.ox.ac.uk \\ * Corresponding author
}

from Ist Congress of the International Foot \& Ankle Biomechanics (i-FAB) community

Bologna, Italy. 4-6 September 2008

Published: 26 September 2008

Journal of Foot and Ankle Research 2008, I(Suppl I):O40 doi:I0.I I86/I757-I I46-I-SI-O40

This abstract is available from: http://www.jfootankleres.com/content/I/SI/O40

(c) 2008 Leitch et al; licensee BioMed Central Ltd.

\section{Introduction}

Functional methods of finding joint axes of rotation involve tracking the movement of one bone at a joint relative to another and subsequent calculation of the joint axis position and orientation from the locations of skinmounted markers. van den Bogert et al. [1] proposed a functional method of deter-mining the non-weight bearing axes of the ankle joint complex. Their subjects performed a full range of motion at the ankle with markers on the shank and shoe. The tech-nique implemented an optimisation algorithm to fit a kinematic model of the subtalar and talocrural joints to the experimentally acquired motion data. Soft tissue movement and associated marker movement was re-ported to be a significant source of error. The aim of the present study was to investigate how this skin movement error might be reduced through a better selection of marker positions.

\section{Methods}

Seven healthy adult subjects ( 5 female and 2 male, age range 16-36) with no history of foot or ankle joint problems participated in the study. Spherical reflective markers were located at eleven anatomical landmarks on the shank and foot (without shoe) $[1,2]$ of ten lower limbs. Three-dimensional spatial data was collected with a 12camera Vicon MX (Vicon Motion Systems, Oxford, UK) as subjects performed plantar- and dorsi-flexion, pronationsupination, and circumduction [1]. Static trials were performed with the foot in both a weight-bearing and a nonweight bearing condition.
The best-fit rigid-body transformations for the shank and foot segments for all motions were calculated using the method of Söder-kvist and Vedin [3]. The reference position for the calculations was taken to be the static trial, first weight-bearing and then non-weight bearing. Skin marker movement during motion was estimated for all combinations of three markers located on the shank and all combinations of three markers located on the foot. This was done by comparing the actual marker positions to those predicted by the best-fit rigid-body transformations [3].

\section{Results}

The skin marker movement error, averaged over all time frames and all subjects, varied with different combinations of markers and different static trials (range 0.96$2.55 \mathrm{~mm}$ for foot, $1.10-7.83 \mathrm{~mm}$ for shank). A reduction in error was achieved when calculations were based on a marker set different from that used by van den Bogert $e t$ al. (Figure 1). The best combination of markers for the foot in the present study was posterior heel distal, posterior heel proximal (wand marker), and sustentaculum tali, with a non-weight-bearing static reference. For the shank, the best marker combination was head of fibula, anterior tibia, and lateral shank (wand marker), with weight-bearing static reference.

\section{Conclusion}

Skin movement error in tracking ankle joint motion can be reduced through a better selection of marker positions. 


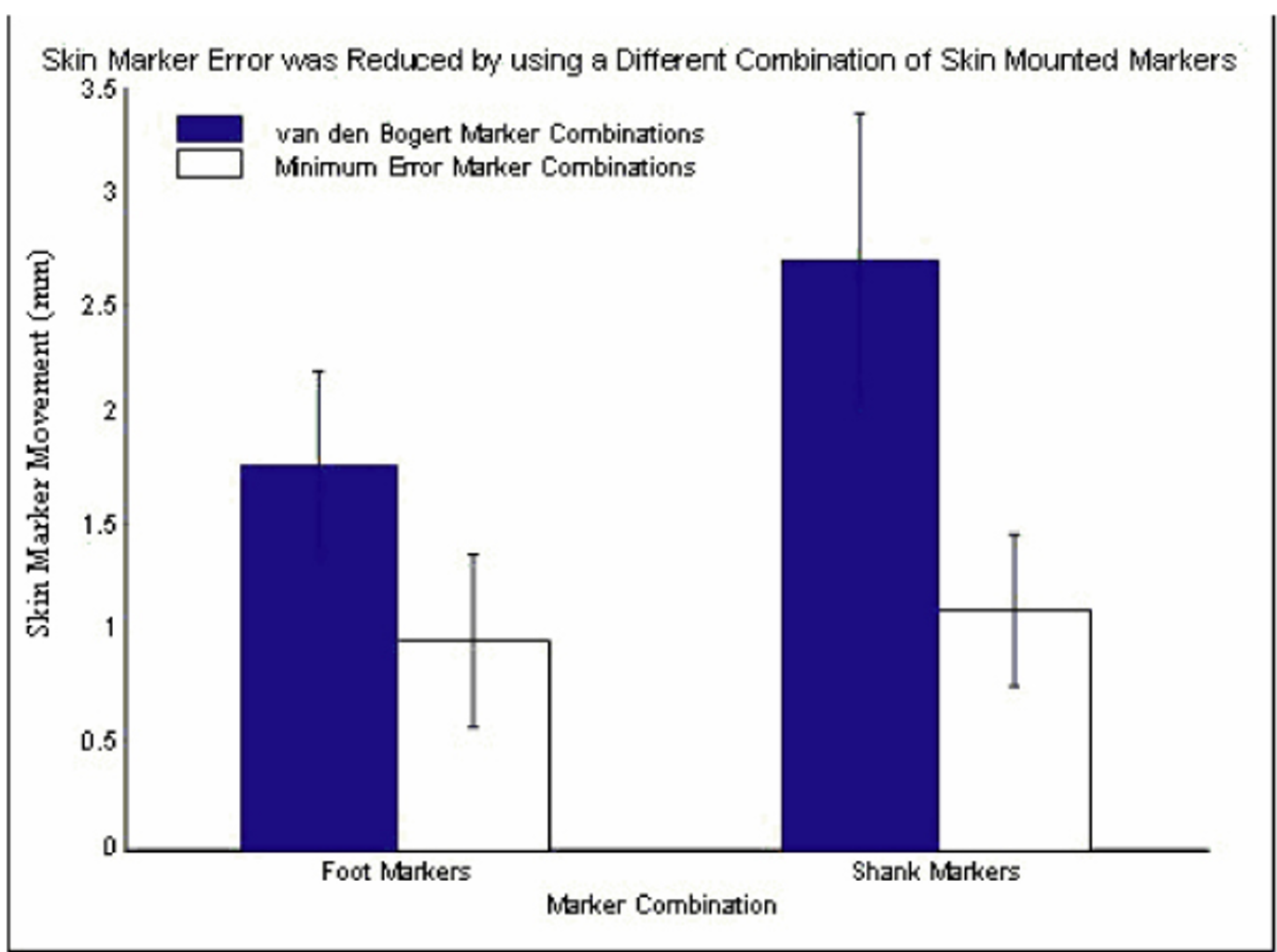

Figure I

Skin marker movement error during the full range of ankle movement.

This in turn should lead to a more accurate prediction of the motion axes of the ankle joint complex.

\section{References}

I. Bogert van den, et al.: / Biomechanics 1994, 27:|477-| 488.

2. Stebbins, et al:: Gait \& Posture 2006, 23:40I-4I0.

3. Söderkvist, et al.: J Biomechanics 1993, 26:1473- I477.

Publish with Bio Med Central and every scientist can read your work free of charge

"BioMed Central will be the most significant development for disseminating the results of biomedical research in our lifetime. "

Sir Paul Nurse, Cancer Research UK

Your research papers will be:

- available free of charge to the entire biomedical community

- peer reviewed and published immediately upon acceptance

- cited in PubMed and archived on PubMed Central

- yours - you keep the copyright
BioMedcentral 